\title{
Investigating Language-related Tasks in EFL Settings in Light of Tele-Collaboration Phenomenon and Sociocultural Theory
}

\author{
https://doi.org/10.3991/ijet.v14i03.9418 \\ Ahmed Abddulateef Al Khateeb( $\left.{ }^{\bowtie}\right)$ \\ King Faisal University, Al-Ahsa, Saudi Arabia \\ ahalkhateeb11@gmail.com \\ Khalid Saeed Alshahrani \\ Royal Commission of Jubail, Jubail Industrial City, Saudi Arabia
}

\begin{abstract}
Understanding the criteria of tele collaborative tasks are essential to boost learners' linguistic, communicative and intercultural competence. This research aims to identify the correlational effect of gender and region on the recognition of the concept of tele collaboration in the sociocultural context of Saudi Arabia. It also focuses on determining and assessing aspects of the criteria of tele collaborative tasks currently employed language-learning settings. One hundred and fifty-five teachers of English as a foreign language (EFL) have randomly participated in this study. It was reported that gender and region have no effect on the practice of tele collaboration. The findings have shown that current language learning tasks match some aspects of the criteria of tele collaborative tasks, such as focusing on meaning, negotiation and being reflection-oriented. Finally, this research has contributed to the assessment of the current sittings of EFL settings and to identifying the extent to which current EFL classes meet tele collaboration requirements.
\end{abstract}

Keywords-Tele collaboration, Tasks, Intercultural communication, Taskbased language teaching (TBLT), EFL

\section{Introduction}

Given the increasingly widespread use of various interactive technologies and tools these days, a huge need to consider how they might be combined with existing language tasks has emerged. The exploration of language-related tasks aims to assess current tasks in English as a foreign language classes (EFL) in light of recent phenomena of tele collaboration, which applies computer-mediated communication. Such investigation would also provide further enlightenment for non-native English teachers to re-design tasks, or at least enhance them so that they are more effective. The analysis of language-related tasks based on the practice of task-based language teaching (TBLT) is the ideal area to attract students' attention as it foster meaningful tasks, along with providing exceptional ways to support, collaborate, interact and communi- 
cate with each other. This research provides quantitative analysis of the type of tasks used in English language teaching classes in general schools in Saudi Arabia. Therefore, the following questions have been addressed as key research questions (RQs):

- RQ1: Does gender affect the recognition of telecollaboration and language exchange practice among Saudi EFL teachers?

- RQ2: Does the city/region affect the recognition of telecollaboration and language exchange practice among Saudi EFL teachers?

- RQ3: Does teaching at specific educational stage and gender have an effect on the criteria of telecollaborative tasks among EFL teachers?

- RQ4: To what extent are current EFL language-learning tasks are telecollaborative; in light of the criteria of telecollaborative tasks?

\section{Socio-Cultural Theory as Theoretical Framework}

Tele collaboration, as indicated by O'Dowd (2013) in the previous section, is an interaction between partners in different geographical locations. Interaction is the process of collaborative exchange of ideas and thoughts between two or more people resulting in a reciprocal effect on each other (Brown, 2001). This study has adopted specific concepts from the Vygotsky Sociocultural Theory to understand the role of technology in mediating interaction in language-related tasks; specifically mediation and activity system, which are, discussed in some depth in this section.

While much of the framework for socio-cultural theory was put forth by Lev Vygotsky, extensions, elaborations, and refinements of sociocultural theory can be found in texts regarding Activity Theory (AT) (Chaiklin and Lave, 1993; Cole and Engeström, 1993). Within the sociocultural tradition, Activity Theory (AT) was developed as a line of theorizing that was an expansion of Lev Vygotsky's original work on Cultural-Historical Psychology, produced in Soviet Russia during the 1920s (Leont'ev, 1981). AT has been developed and used as a tool for systematically analysing different kinds of human practices. Based on Vygotsky's Sociocultural Theory, interaction is the source of development. Vygotsky emphasised that learning and development is a mediated process which implies its dialectical and reflexive nature (Daniels, 2001). Collaboration is achieved through interaction be it in physical or virtual space in which participants negotiate meaning in order to reach to conclusion or shared understanding. This negotiation is mediated by tools within the sociocultural context in which the activity is embedded.

Mediation is a central concept of the sociocultural theory. This is evident in the emphasis of the theory on social factors and the interaction between people and their environments (Cole, 1999). Engeström (1999) explains mediation 'The idea is that humans can control their own behaviour - not from the inside, on the basis of biological urges, but from the outside, using and creating artefacts' (p. 29). Mediation is achieved through the help of tools which can be physical or part of virtual reality. In the context of the current study, language and technology are mediating tools for teachers' interaction. When regarding teachers' interaction during EFL tasks as an 
activity system, technology is the mediating artefact in that particular 'activity system'.

The notion of activity system as shown in Figure 1 was developed by Yori Engeström in his efforts to develop Activity Theory (AT). Such efforts resulted in the development of the activity system model (Figure 1) which is a tool that is descriptive in nature rather than prescriptive (Nardi, 1996). Engeström defined activity systems as 'object-oriented, collective, and culturally mediated human activity' (Engeström and Miettinen, 1999, p. 9). The Activity System model includes six constituents: subject, Object, tools, community, rules and division of labour. In the case of this research, the telecollaborative learning environment can be considered as the activity system in which technology used as a tool to mediate interaction between teachers (subjects) during the same activity.

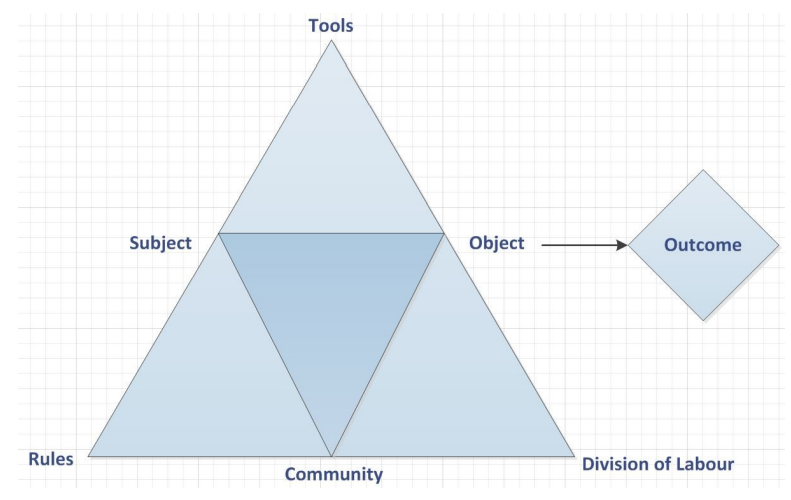

Fig. 1. Activity System Model (Engeström, 1987)

\section{Literature Review}

\subsection{Tele-collaborative learning environment}

The development of synchronous and asynchronous web-oriented communication has revolutionized the ways that individuals can learn and interact. This has resulted in what is known as networked-based language learning (Kern, Ware and Warschauer, 2008) or tele collaborative language learning for disseminating intercultural communication between individuals from various cultural and linguistic backgrounds (Belz, 2002).

Telecollaboration is an example of a new way of working which can encourage a pair or a group of language learners to collaborate with the aim of augmenting their knowledge in first and second/foreign language (Bower and Kawaguchi, 2011). Telecollaboration is seen as 'an educational endeavor that involves people in different locations using Internet tools and resources to work together' (Harris, 1999: 55). Telecollaboration has also been defined as the 'virtual interaction and exchange projects between classes of partners in geographically distant locations' (O’Dowd, 2013). 
Tele collaborative-oriented environments provide members with cost-effective access and engagement with expert peers in the target language, and results in an increase in intercultural awareness and their linguistics proficiency. Furthermore, in tele collaborative learning projects, internationally located learners become familiar with various web-based communicative, most likely interactive, tools to practice social interaction, sharing of knowledge and intercultural exchange (Belz, 2003). There are four key benefits to participating in tele collaborative learning partnerships or 'online collaborative learning' as declared by Redmond and Lock (2006) Firstly, online collaborative learning provides access to multiple and unlimited learners. Secondly, it fosters learning anywhere at any time. Thirdly, it helps individuals to move from their private sphere to being open to the world. Lastly, it supports the establishment of learning communities with experts at local, national and international levels.

Tele collaboration exchanges are usually based on precise tasks with the aim of developing language skills and intercultural communicative competence (Coutinho, 2016). Furthermore, they support the principles of indirect language learning through learning more about the target culture (Guth and Helm, 2011). Several studies have drawn attention to the significance of intercultural communicative competence in general (Guilherme, 2000) and in telecollaborative learning settings in particular (O'Dowd, 2007). For instance, O'Dowd (2007) reported that that telecollaborative tasks have the affordance to sustain language learners' intercultural communicative competence.

Nonetheless, constructing a tele collaborative learning environment remains to be a complex process, which requires specific competences and skills (i.e., communicative, pedagogic, linguistic and digital competences) as shown by Guth, S., Helm, and O'Dowd (2012) that need to be met by instructors and learners. O'Dowd (2013) identified possible obstacles related to the telecollaborative learning environment by interviewing several experienced telecollaborative practitioners. They acknowledged the following difficulties: finding additional time, integrating it into traditional classes and in assessment, finding appropriate partners and providing teachers with the technological knowledge and e-literacy needed.

\subsection{Task Desing and TBLT}

Designing tasks is at the heart of creating successful tele collaborative learning environments and achieving competences needed (Hampel, 2010). From a second language acquisition (SLA) perspective, tasks have been broadly used to stimulate language production, promote language interaction, negotiate meaning, process input and focus on form (Van den Branden, 2016). Ensuring tasks are satisfactory is a key element in the process of designing tasks, since tasks are the agent which leads learners to better understand the knowledge, as well as enhancing the quality of learning process (Furstenberg, 1997). Task design is one of the principal factors considered in language development research along with the nature of implementation and evaluation of such tasks, as demonstrated by Furstenberg (1997).

Numerous studies have explored the structure and components of soundly designed tasks. Meskill (1999) put forward a list of criteria for task design which concentrated 
on pedagogic approach to language learning. Meskill emphasizes the significance of providing multiple answers to problems given as being motivating, interesting and encouraging, challenging and related to real world. Undeniably, the role of tasks and, with that, task design has also always been a crucial issue when designing telecollaborative learning environments or projects (Hampel, 2010; Hauck, 2010; Thomas and Reinders, 2010). Nevertheless, designing tasks for telecollaborative learning environments remains demanding as it requires instructors to take into account: pedagogical, technical, linguistic and intercultural factors (Kurek and Müller-Hartmann, 2017).

The term task-based language teaching (TBLT) was originally coined by second language acquisition (SLA) researchers and language experts, with this type of task design being a response to teachers dominating the teaching process and formoriented practice in language learning (Long and Norris, 2000). TBLT has been extensively researched in relation to language learning and language education (Van den Branden, Bygate and Norris, 2009). In such research studies, it was informed that the TBLT on the idea learning by doing or experiential learning with the aim to fulfil communicative competence using the target language.

A crucial consideration of TBLT is the effect of task design and its relevant interaction and communicative competence elements through the facilitation of technologies, with a number of factors being significant, including task type, number of participants, task difficulty, task duration, etc. Yet, results have shown no consistency, as some researchers have found task type has no significant impact (Keller-Lally, 2006) while others identified jigsaw tasks as being a better task for promoting meaningful interaction (Blake, 2000).

Tasks play a key role in TBLT. Nunan (2004) differentiated between tasks and activities. In this regard, Long (1985) has emphasized that tasks must be related to what individuals do in everyday life situations, in authentic contexts and goal-based environments. Ellis (2003) has distinguished tasks from other types of activities, due to the fact that they are meaning-focused, communicative in nature and content-oriented and highly value the fulfilment of a task goal and its expected outcome. Bachman and Palmer (1996) also agree that a task involves individuals in using language for the purpose of fulfilling particular objectives in particular contexts with the emphasis on meaning. In view of that, Ellis (2003) identified a working definition of task, which is comprised of six criteria as stated below:

'Tasks involve a plan for learner activity; they have a primary focus on making meaning; they engage with real-world authentic language use; they focus on any or all of the four language skills; they engage learners in cognitive skills in order to accomplish them; and they have a defined communication-based learning outcome'. (p: 910)

This emphasis on task design in general and on telecollaborative task design in particular was based on what Furstenberg (1997) expresses as follows:

'Our main role, then, is to design a task (...) since the task is what gives meaning to the learners' explorations. Only well-designed task can ensure the quality of the learning process - which is a teacher's ultimate responsibility' ( $\mathrm{p}: 24$ ).

Therefore, tasks are required to be carefully designed, taking into account students' interpretation of tasks and their awareness of the benefits and challenges of technolo- 
gy (Kurek and Muller-Hartmann, 2017). As a matter of fact, the advent of technologies and computer-mediated communication (CMC) tools have largely influenced task design and TBLT and, accordingly, several research projects have focused on identifying the impact of task-based CMC on language progress and the learning progress (Lee, 2002). Sykes, Oskoz and Thorne (2008) argue that the area of task design and TBLT has been incredibly revitalized by the arrival of various technologies other than CMC such as tasks involving web-based spaces (González-Lloret, 2003). TBL focuses on the definition of a task. For instance, Nunan (2006) suggests a task as

'A piece of classroom work that involves learners in comprehending, manipulating, producing or interacting in the target language while their attention is focused on mobilizing their grammatical knowledge in order to express meaning, and in which the intention is to convey meaning rather than to manipulate form' (p: 17). Furthermore, Van den Branden (2006) argues that a task is: 'an activity in which a person engages in order to attain an objective, and which necessitates, the use of language' ( $p$ : 20).

According to the same researchers, TBL has pedagogical influences because it includes activities, involvement, purpose and language use. Furthermore, TBL is not an isolated theory since it is always part of others such as theories such as second language acquisition theories. In addition, TBL is used to promote accuracy and accuracy and the integration of the four skills language learning comprises (Ellis, 2003). Moreover, not only do such tasks help learners to become more flexible and motivated to learn, but they can also help teachers to better plan what they teach. What is more, TBLT should always be a feature of classroom practice to promote successful language learning and teaching (Robinson, 2011). Indeed, according to Robinson (2011), designing meaningful tasks for learning has become popular because of the following: they provide corrective feedback; they offer opportunities for noticing a gap in knowledge; they promote re-conceptualizing and re-thinking; they afford negotiation and comprehension of meaning and they promote interlanguage.

In line with Willis (1996), task-based learning involves three stages: Firstly, pretask which entails introducing the topic and enabling learners to engage in the learning process. Secondly, task-cycle, which involves tasks being performed in pairs or in groups. Thirdly, language focuses, which requires teachers and peers to give feedback to students, thus enabling learners to draw conclusion about what they have learnt.

\subsection{CALL/Technology-oriented TBLT}

Computer-assisted language learning (CALL) and a number of other technologies play a pivotal role in TBLT and language learning. Numerous studies have investigated the influence of emerging technologies (such as web 2.0 interactive tools) on different types of tasks, which are unlikely to be implemented in face-to-face settings (González-Lloret, 2016). González-Lloret (2016) argues that TBLT is seen as an ideal platform for the comprehensive realization of the potential uses of technological innovations for pursuing language-learning development. 
The adoption of such technologies has even gone beyond ordinary use in language learning and teaching to embrace changes in students' living and learning practices (Rosen, 2010). There are always robust synergies between the two fields given: CALL and TBLT (Thomas and Reinders, 2010), since learners can engage in activities through technology-mediated transformation and creation processes rather than just reading about language and culture in textbooks' (González-Lloret and Ortega 2014: p. 3). The interest in technology-oriented TBLT is a rapidly growing field because technologies could take part in promoting learners to further understand, experience and share their relationships with the world in an unprecedented way.

In view of that, Chapelle $(2001 ; 2003)$ develops a number of criteria for task design based on second language acquisition (SLA) theories and the medium of computerassisted language learning. Chapelle's criteria include learner fit, meaning focus, authenticity, positive impact and practicality.

\section{$4 \quad$ Research Methodology}

The purpose of the current research is to discover the correlational effect of gender, city and teaching at specific educational stage with the recognition of the term 'telecollaboration' and language exchange practice as well as on the various criteria of telecollaborative tasks (RQ1, RQ2 and RQ3). It will also explore the type of tasks employed in EFL language learning classes in light of telecollaboration and its related practices (RQ4).

This research is expected to reveal further understanding and awareness of this issue including verifying the nature of current tasks used in English language teaching classes. Instructors' self-assessment of such tasks will also be beneficial in advancing their knowledge and promoting personal awareness of their teaching practices. Furthermore, this research will employ a standardized questionnaire by Kurek and Muller-Hartmann (2017), however, a few amendments have been made to make it more appropriate for the participants according to their research context. It will be used in conjunction with a chi square test, which is a statistic hypothesis test that is used explore correlation for independence.

The questionnaire is built on three major principles for designing satisfactory EFLrelated tasks:

- They have the potential to support learning, including challenging learners

- Tasks are clearly communicated and structured

- Tasks should consider inter-cultural communicative competence learning and multiliteracies.

As far as the research participants were concerned, the questionnaire was completed by one hundred and fifty-five (155) English language teachers, both males and females, working at different stages (primary, intermediate and secondary) in government schools across Saudi Arabia. Teachers employed at private or international schools were exempt as they may follow a different system. The participants involved in the study had had a variety of different teaching experiences, came from diverse 
educational backgrounds and were of different ages. There was also an interest in exploring the qualifications of the participating EFL teachers (i.e. diploma, bachelor, etc.).

The context of the research is Saudi Arabia where English is mostly considered as a foreign language. There have been several attempts to enhance the teaching of English as a foreign language by improving textbooks and providing necessary infrastructure such as language labs. Nevertheless, many students continue to lack motivation and the essential skills needed to communicate and comprehend others' target cultures. It is believed that designing unusual sort of tasks for language learning, such as identifying suitable telecollaborative tasks, might change the situation.

\section{$5 \quad$ Research Findings and Data Analysis}

The researchers investigated the first issue of inquiry which is concerned with the correlation between Saudi EFL teachers' gender and their knowledge of the term 'telecollaboration' and language exchange practice. The statistical analysis used chi2 as it displays Pearson's chi-squared test for the hypothesis, so that the rows and columns in a two-way table are independent. If $p$-value $<0.05$, we reject the null hypothesis of independence. In our case we cannot reject the null hypothesis of independence between the variables of recognition of telecollaboration and gender as the p-value at a global level is (0.428). This means that the difference in gender does not have an effect on recognition of telecollaboration and language exchange practice. This result also indicates that it is not necessarily the case that when one variable increases or changes the other variable will increase or change too.

Furthermore, the findings show that the majority of the EFL teachers (nearly 95\%), including females and males, have at least heard about the term telecollaboration, even if they have not necessarily applied it in the EFL classroom. Similar percentage of teachers (nearly 90\%) also indicated their ignorance of this term and its relevant practices whereas only a minority (nearly $15 \%$ ) expressed the fact that they are fully aware of this term including the unusual tasks involved. Nevertheless, a critical issue still remains, that is to say whether or not such employment of telecollaborative tasks is being done so accurately and in line with the standards and criteria of utilizing telecollaboration; which was identified in the literature.

Table 1. Pearson chi $2=1.6986 \operatorname{Pr}=0.428$

\begin{tabular}{|c|c|c|c|}
\hline \multicolumn{4}{|l|}{ Gender } \\
\hline Recognition of tele collaboration/Language exchange practice & Female & Male & Total \\
\hline I am fully aware of such terms. I have used them in my teaching. & $\begin{array}{c}6 \\
6.74 \% \\
\end{array}$ & $\begin{array}{c}5 \\
7.69 \% \\
\end{array}$ & $\begin{array}{c}11 \\
7.14 \% \\
\end{array}$ \\
\hline $\begin{array}{l}\text { I have heard about them before. Yet, I do not have adequate details or } \\
\text { knowledge. }\end{array}$ & $\begin{array}{c}38 \\
42.70 \%\end{array}$ & $\begin{array}{c}34 \\
52.31 \%\end{array}$ & $\begin{array}{c}72 \\
46.75 \%\end{array}$ \\
\hline I have not heard about them before at all. & $\begin{array}{c}45 \\
50.56 \%\end{array}$ & $\begin{array}{c}26 \\
40 \%\end{array}$ & $\begin{array}{c}71 \\
46.10 \% \\
\end{array}$ \\
\hline Total & $\begin{array}{c}89 \\
100 \%\end{array}$ & $\begin{array}{c}65 \\
100 \%\end{array}$ & $\begin{array}{c}154 \\
100 \%\end{array}$ \\
\hline
\end{tabular}


Furthermore, a second issue being experimented by this research, as the second research indicates, is to explore the correlation between the regions (Central, Northern, Southern, etc.) Saudi EFL teachers come from and their familiarity with the term 'telecollaboration' or language exchange practice. Thus, a statistical analysis of chi2 was used to calculate and display Pearson's chi-squared for the hypothesis that the rows and columns in a two-way table are independent. If $\mathrm{P}$-value $<0.05$ we reject the null hypothesis of independence. As reported earlier, in this case we cannot reject the null hypothesis of independence too between the variables of recognition of telecollaboration and region either, as the p-value at a global level is (0.246) as shown in Table 2. This means that geographical locations do not have an effect on recognition of telecollaboration and language exchange practice. In other words, there is perhaps no linear relationship between these two given variables.

The findings of the analysis confirm that only a minority (7.14\%) of EFL teachers are fully aware of the term telecollaboration and language exchange practice. As shown in Table 1, similar percentages have been identified between EFL teachers who have heard this term but who lack the knowledge necessary to apply it successfully in reality, and those who have never heard of this term at all $(72 \%$ and $71 \%$ respectively).

Table 2. Pearson chi $2=10.2839 \operatorname{Pr}=0.246$

\begin{tabular}{|c|c|c|c|c|c|c|}
\hline \multicolumn{7}{|c|}{ City/region } \\
\hline $\begin{array}{c}\text { Recognition of tele } \\
\text { collaboration/Language } \\
\text { exchange practice }\end{array}$ & Central & Eastern & Northern & Southern & Western & Total \\
\hline $\begin{array}{l}\text { I am fully aware of such } \\
\text { terms. I have used them } \\
\text { in my teaching. }\end{array}$ & $\begin{array}{c}2 \\
10 \%\end{array}$ & $\begin{array}{c}1 \\
2.38 \%\end{array}$ & $\begin{array}{c}0 \\
0 \%\end{array}$ & $\begin{array}{c}0 \\
0 \%\end{array}$ & $\begin{array}{c}8 \\
10 \%\end{array}$ & $\begin{array}{c}11 \\
7.14 \%\end{array}$ \\
\hline $\begin{array}{l}\text { I have heard about them } \\
\text { before. Yet, I don't have } \\
\text { adequate details or } \\
\text { knowledge. }\end{array}$ & $\begin{array}{c}11 \\
55 \%\end{array}$ & $\begin{array}{c}24 \\
57.14 \%\end{array}$ & $\begin{array}{c}1 \\
100 \%\end{array}$ & $\begin{array}{l}7 \\
63.64 \%\end{array}$ & $\begin{array}{c}29 \\
36.25 \%\end{array}$ & $\begin{array}{c}72 \\
46.75 \\
\%\end{array}$ \\
\hline $\begin{array}{l}\text { I have not heard about } \\
\text { them before at all. }\end{array}$ & $\begin{array}{c}7 \\
35 \%\end{array}$ & $\begin{array}{c}17 \\
40.48 \%\end{array}$ & $\begin{array}{c}0 \\
0 \%\end{array}$ & $\begin{array}{c}4 \\
36.36 \%\end{array}$ & $\begin{array}{c}43 \\
53.75 \%\end{array}$ & $\begin{array}{c}71 \\
46.10 \\
\%\end{array}$ \\
\hline Total & $\begin{array}{c}20 \\
100 \% \\
\end{array}$ & $\begin{array}{c}42 \\
100 \% \\
\end{array}$ & $\begin{array}{c}1 \\
100 \% \\
\end{array}$ & $\begin{array}{c}11 \\
100 \% \\
\end{array}$ & $\begin{array}{c}80 \\
100 \% \\
\end{array}$ & $\begin{array}{c}154 \\
100 \% \\
\end{array}$ \\
\hline
\end{tabular}

As far as the third research question is concerned, it attempted to explore the correlation between teaching at a specific educational stage (primary, intermediate and secondary) and various criteria of telecollaborative tasks among EFL teachers. Consequently, the researcher performed multivariate tests on means for the variables on the basis of using the ordinal variables: Strongly disagree $=1$; Disagree $=2$; Undecid$e d=3 ;$ Agree $=4$ and Strongly disagree $=5$. The analysis has shown equal means across the three groups of EFL teachers teaching in the three educational stages at a global level as shown in Chart 1. This is the multivariate Behrens-Fisher problem. With more than two groups, the Wald test, with p-values adjusted as proposed by James (1954), is displayed. The findings have shown that $\mathrm{p}$-values are less than $5 \%(<0.05)$; for that reason, we can say that the means of variables between the three groups of educational stages are different at the $5 \%$ significance level. 
Therefore, it was found that educational stages may have a correlational effect on the differences in task types used by EFL teachers; based on the criteria of telecollaborative tasks. Furthermore, the Wald chi-square test and the likelihood ratio test (LR chi2) produced similar results as shown below:

Test for equality of educational stages (three group means), allowing for heterogeneity

Wald chi2 $=108.14$

Prob $>$ chi $2=0.0000$ (chi-squared approximation)

Test for equality of educational stages (three group means), allowing for heterogeneity

LR chi2 $=77.73$

Prob $>$ chi2 $=0.0189$ (likelihood ratio test)

Moreover, the same research question (RQ3) attempts to find out the correlation between gender and various criteria of telecollaborative tasks among EFL teachers. Accordingly, the analysis has shown that gender may have no correlational effect on the various criteria of telecollaborative tasks. There is no difference of means between male and female ( $p$-value $>0.05$ ) as the MNV shows below:

Test for equality of gender (2 group means), allowing for heterogeneity

$\operatorname{MNV} F(27,106.9)=0.96$

Prob $>\mathrm{F}=0.5329$

Test for equality of gender ( 2 group means), allowing for heterogeneity

LR chi2 $=29.15$

Prob $>$ chi2 $=0.3539$

As far as the fourth research question is concerned, it seeks to determine the type of language learning tasks currently used in EFL settings. Using a likert-scale, ranging from strongly agree to strongly disagree for the criteria related to telecollaborative tasks, the findings are diverse and the responses between male and female are very different, particularly for preventing copy-paste use of information, activating various levels of processing and evaluation and allowing doe discovering new aspects of engaged cultures. Other criteria have been identified with equal responses among participants such as (promoting the benefits of recent technologies).

Generally speaking, the analysis has shown that the majority of Saudi EFL teachers agree, though not strongly agree, with various criteria of telecollaborative tasks in their assigned language learning tasks such as (dividing tasks into achievable steps). On the other hand, a minority of the teachers strongly agreed on the importance of applying the criteria of telecollaborative tasks in their language teaching such as (organizing tasks according to their complexity). The participants' responses with regard to statements, they strongly disagreed were limited, confirming that their assigned tasks are not entirety lacking some aspects of telecollaborative aspects such as (pro- 
moting intensive communication), (using authentic resources) and (promoting intercultural evaluation).

\section{Discussion and Conclusion}

As shown earlier, gender and region has no effect on Saudi EFL teachers' ability to recognize the term telecollaboration and incorporate it into language exchange practice. These results seem to be logical as gender and region factors are static factors, whereas tele collabotion is dynamic. Telecollaboration is dynamic in the sense that it deals with the application of web-based tools to bring people (of any gender) and classes (in any region) together for the sake of enhancing EFL and communicative competence (O'Dowd, 2011).

Therefore, the participants have begun to be aware of the possible ways of developing intercultural communicative competence-related tasks by employing multimodal use of combined web-oriented tools (Hauck, 2010).

The results indicated the significant relationship between telecollaborative language learning tasks and the educational stage. This involves the importance of assigning well-thought-out specific tasks with determining their expected outcomes. This is consistent with Coutinho (2016) who claims that successful tele collaboration and tele collaborative practices are centered on well-defined tasks with the consideration of enhancing language skills in addition to intercultural understanding. These tasks should meet the instructor's curriculum design and include problem-solving and decision-making tasks and themes such as annual events, trips, etc. (Akiyama, 2016).

The results of the current study revealed that EFL teachers have an interest in telecollaboration and its practice in EFL classes. It has been shown that the majority of the teachers are designing tasks that reflect some aspects of telecollaborative tasks such as dividing tasks into achievable steps and also taking into account the logical sequence and gradual order of tasks.

Yet, the results also show the lack of adequate expertise in this field with regard to dealing with designing sound tasks that guarantee students' engagement to improve their linguistic and intercultural competence as expressed by Schenker (2012). For instance, it has been discovered that teachers need to expose learners to intensive communication using more authentic resources. EFL teachers should also encourage learners to practise intercultural evaluation.

In order for this to be achieved, language exchange practices in Saudi EFL context should be designed using a more holistic approach that considers all different aspects. To understand this from a sociocultural perspective, EFL tasks needs to be designed as an 'activity system' where technology and pedagogical and technological training act as 'tools' that mediate teachers' interaction in such tasks. Activity dynamics including interaction between teachers in telecollaborative tasks are directed towards realizing the 'object' of the same activity system (see Figure. 1).

However, the activity is bound by rules and the roles of different parties directly or indirectly involved to that particular activity. This includes rules and regulations at different levels (i.e. curriculum, school, regional directorate, and ministerial level). 
The Saudi educational system is undergoing rapid changes as part of the Ministry of Education's efforts to respond to the national transformational plans of Saudi Vision 2030.

In addition to the rules governing the determination of specific activities, there are other stakeholders who play different roles and as a consequence will have an impact on the dynamics of the activity. That is to say, when EFL teachers are engaged in telecollaborative tasks, they are not isolated from their local environment. Fellow teachers as well as school and ministry administrators have the power to either facilitate or hinder teachers' interaction, which can create 'contradictions' between different parts of the activity. This might also explain the correlation between the types of EFL telecollaborative tasks and educational stages that do exist when it comes to participants' gender or region, as shown in this study.

The current changes and interruption to the educational system - driven by the ministry - is affecting the whole country. Indeed, there is a pressing need to take this unprecedented and rapid changing context into consideration when designing teaching and learning tasks for EFL teachers in Saudi Arabia.

Due to the nature of the research problem, issues under investigation and research questions, this research took a primarily quantitative approach. This means that the findings may not apply to the entire EFL teaching community. A possible future study, which would support the current data, is to conduct a qualitative-oriented study by interviewing a group of EFL teachers, to investigate and identify the type of language learning tasks implemented in EFL settings. Interviews should focus on seeking answers for the following questions:

- How do you normally design tasks and on what bases?

- Do you like to invent new types of tasks, which are based on interaction for example? Why?

- What do you think about existing tasks including merits and demerits, and how can they be developed? Do you think that they can enhance the language learners' communicative and linguistic competence?

- Do you find L2 learners fully engaged in classes featuring such tasks? What kind/type of tasks currently exist in textbooks?

- What might be some of the sociocultural factors that facilitate or hinder these tasks in other contexts?

\section{$7 \quad$ References}

[1] Akiyama, Y. (2016). Learner Beliefs and Corrective Feedback in Telecollaboration: A Longitudinal Investigation. System, 64, 1-25.

[2] Bachman, L. F. and Palmer, A. S. (1996). Language Testing in Practice: Designing and Developing Useful Language Tests. Oxford: Oxford University Press.

[3] Belz, J. A. (2002). Social Dimensions of Telecollaborative Foreign Language Study. Language learning and Technology, 6 (1), 60-81.

[4] Belz, J. (2003). Linguistic Perspectives on the Development of Intercultural Competence in Telecollaboration. Language Learning and Technology, 7 (2), 68-99. 
Paper-Investigating language-related tasks in EFL Settings in light of Tele-collaboration phenomenon...

[5] Blake, R. (2000). Computer Mediated Communication: A Window on Spanish L2 Interlanguage. Language Learning and Technology, 4(1), 120-136.

[6] Bower, J. and Kawaguchi, S. (2011). Negotiation of Meaning and Corrective Feedback in Japanese/English eTandem. Language Learning and Technology, 15, (1), 41-71.

[7] Brown, H. (2001).Teaching by Principles. An Interactive Approach to Language Pedagogy. New York: Addison Wesley Longman, Inc.

[8] Chaiklin, S. and Lave, J. (eds.), (1993). Understanding practice: Perspectives on Activity and Context. Cambridge: Cambridge University Press. https://doi.org/10.1017/CBO9780511625510

[9] Chapelle, C. A. (2001). Computer Applications in Second Language Acquisition. Cambridge: Cambridge University Press. https://doi.org/10.1017/CBO9781139524681

[10] Chapelle, C. (2003). English Language Learning and Technology: Lectures on Applied Linguistics in the Age of Information and Communication Technology. The Netherland: John Benjamins Publishing. https://doi.org/10.1075/1llt.7

[11] Cole, M. (1999). Cultural Psychology: Some General Principles and A Concrete Example. In Y. Engeström, R. Miettinen and R. Punamaki (eds.), Perspectives on Activity Theory (p: 87-106). Cambridge: Cambridge University Press. https://doi.org/ 10.1017/CBO9780511812774.008

[12] Cole, M. and Engeström, Y. (1993). A Cultural -historical Approach to Distributed Cognition. In G. Salomon (ed.), Distributed Cognitions: Psychological and Educational Considerations (p: 1-46). New York: Cambridge University Press.

[13] Coutinho, M. (2016). Using a Telecollaboration Exchange Web 2.0 in a Second Language Classroom. US-China Education Review, 6(10), 603-609.

[14] Daniels, H. (2001). Vygotsky and Pedagogy. London: Routledge Falmer.

[15] Ellis, R. (2003). Task-based Language Learning and Teaching. Oxford: Oxford University Press.

[16] Engeström, Y. (1987) Learning by Expanding: an Activity-theoretical Approach to Developmental Research, Helsinki: Orienta-Konsultit.

[17] Engeström, Y. (1999). Activity Theory and Individual and Social Transformation. In Y. Engeström, R. Miettinen and R. Punamaki (eds.), Perspectives on activity theory (p: 1938). New York: Cambridge University Press. https://doi.org/10.1 017/CBO9780511812774.003

[18] Engeström, Y. and Miettinen, R. (1999). Introducation. In Y. Engeström, R. Miettinen and R. Punamaki (eds.), Perspectives on Activity Theory (p: 1-16). New York: Cambridge University Press. https://doi.org/10.1017/CBO9780511812774.002

[19] Furstenberg, G. (1997). Teaching with Technology: What is at Stake. ADFL Bulletin, 28(3), 21-25. https://doi.org/10.1632/adfl.28.3.21

[20] González-Lloret, M. (2003). Task-based language materials: En busca de esmeraldas. Language Learning and Technology, 7(1), 86-104.

[21] González-Lloret, M. (2016). A Practical Guide to Integrating Technology into Task-based Language Teaching. Washington, DC: Georgetown University Press.

[22] González-Lloret, M. and Ortega, L. (2014). Technology-mediated TBLT: Researching Technology and Tasks. Towards technology-mediated TBLT (eds.). The Netherlands: John Benjamins Publishing Company.

[23] Guilherme, M. (2000). Intercultural Competence. In Byram, M. (ed.), Routledge Encylopaedia of Language Teaching and Learning (p: 297-300). London: Routledge.

[24] Guth, S. and Helm, F. (2011). Developing Multiliteracies in ELT through Telecollaboration. ELT journal, 66(1), 42-51. https://doi.org/10.1093/elt/ccr027 
[25] Guth, S., Helm, F. and O'Dowd, R. (2012). University Language Classes Collaborating Online: A Report on the Integration of Telecollaborative Networks in European Universities. INTENT Project team.

[26] Hampel, R. (2010). Task Design for a Virtual Learning Environment in a Distant Language Course. In M. Thomas and H. Reinders (eds.), Task-based Language Learning and Teaching with Technology (p: 131-153). London: Continuum Publishing.

[27] Harris, J. (1999). First Steps in Telecollaboration. Learning and Learning with technolo$g y, 27,54-57$.

[28] Hauck, M. (2010). The Enactment of Task Design in Telecollaboration 2.0. In M. Thomas and H. Reinders (eds.), Task-based Language Learning and Teaching with technology (p: 197-217). London, UK: Continuum.

[29] Keller-Lally, A. (2006). Effect of Task-type and Group Size on Foreign Language Learner Output in Synchronous Computer-mediated Communication. Unpublished doctoral dissertation. University of Texas: Austin, USA.

[30] Kern, R., Ware, P. and Warschauer, M. (2008). Network-based Language Teaching. Encyclopedia of Language and Education, 4, 281-292. https://doi.org/10.1007/978-0-387$\underline{30424-3 \quad 105}$

[31] Kurek, M. and Müller-Hartmann, A. (2017). Task Design for Telecollaborative Exchanges: In Search of New Criteria. System, 64, 7-20. https://doi.org/10.1016/j.system.2016.12.004

[32] Lee, L. (2002). Enhancing Learners' Communication Skills through Synchronous Electronic Interaction and Task-based Instruction. Foreign Language Annals, 35(1), 16-24. https://doi.org/10.1111/j.1944-9720.2002.tb01829.x

[33] Long, M. H. and Porter, P. A. (1985). Group Work, Interlanguage Talk, and Second Language Acquisition. TESOL Quarterly, 19(2), 207-228. https://doi.org/10.2307/3586827

[34] Long, M.H., Norris, J. M. (2000). Task-based Teaching and Assessment. In Byram, M. (ed.), Encyclopedia of Language Teaching (p: 597-603). London: Routledge.

[35] Meskill, C. (1999). Computers as Tools for Sociocollaborative Language Learning. In K. Cameron (ed.), Computer-assisted Language Learning (CALL): Media, Design and Applications (p: 144-152). Exton, PA: Swets and Zeitlinger Publishers.

[36] Nardi, B. (1996). Activity Theory and Human-computer Interaction. In B. Nardi (ed.), Context and Consciousness: Activity Theory and Human-computer interaction (p: 7-16). Cambridge: The MIT Press.

[37] Nunan, D. (2004). Task-based Language Teaching. Cambridge: Cambridge University Press. https://doi.org/10.1017/CBO9780511667336

[38] Nunan, D. (2006). Task-based Language Teaching in the Asia Context: Defining 'task'. Asian EFL Journal, 8(3), 12-18.

[39] O’Dowd, R. (ed.), (2007). Online Intercultural Exchange: An Introduction for Foreign Language Teachers. Clevedon: Multilingual Matters. https://doi.org/10.21 832/9781847690104

[40] O'Dowd R. (2011) Online Foreign Language Interaction: Moving from the Periphery to the Core of Foreign Language Education. Language Teaching Journal, 44 (3), 368-380. https://doi.org/10.1017/S0261444810000194

[41] O'Dowd, R. (2013). Telecollaborative Networks in University Higher Education: Overcoming Barriers to Integration. The Internet and Higher Education, 18, 47-53. https://doi.org/10.1016/j.iheduc.2013.02.001

[42] Redmond, P. and Lock, J. V. (2006). A Flexible Framework for Online Collaborative Learning. The Internet and Higher Education, 9(4), 267-276. https://doi.org/10.1016/j.iheduc.2006.08.003 
[43] Robinson, P. (2011). Task-based Language Learning: A Review of Issues. Language Learning, 61, 1-36. https://doi.org/10.1111/j.1467-9922.2011.00641.x

[44] Rosen, L. D. (2010). Rewired: Understanding the iGeneration and the way they learn (1 ${ }^{\text {st }}$ edition). New York, NY: Palgrave Macmillan.

[45] Schenker, T. (2012). Intercultural Competence and Cultural Learning through Telecollaboration. CALICO Journal, 29(3), 449-470. https://doi.org/10.11139/cj.29.3.449-470

[46] Sykes, J. M., Oskoz, A. and Thorne, S. L. (2008). Web 2.0, Synthetic Immersive Environments, and Mobile Resources for Language Education. CALICO Journal, 25 (3), 528-546. https://doi.org/10.1558/cj.v25i3.528-546

[47] Thomas, M. and Reinders, H. (eds.), (2010). Task-based Language Learning and Teaching with Technology. London, UK: Continuum.

[48] Van den Branden, K. (2006). Task based Language Education. From Theory to Practice. Cambridge: Cambridge University Press. https://doi.org/10.10 17/CBO9780511667282

[49] Van den Branden, K. (2016). Task-based Language Teaching. In H. Graham (ed.), The Routledge Handbook of English Language Teaching (p. 238- 251). Oxon: Routledge.

[50] Van den Branden, K., Bygate, M. and Norris, J. (eds.), (2009). Task-based Language Teaching: A Reader. Amsterdam: John Benjamins. https://doi.org/10.1075/tblt.1

[51] Willis, J. (1996). A Flexible Framework for Task-based Learning. Harlow, England: Longman.

\section{Authors}

Dr Ahmed Abdulateef Al Khateeb works currently as an Assistant Professor of English and the Head of the Department of English Language at the College of Arts, King Faisal University, Saudi Arabia. He holds a PhD in Applied Linguistics and languages learning technologies, from the University of Southampton, Graduate School of Humanities, Modern Languages, United Kingdom. He has authored several research papers including book chapters and scholarly articles. His research interests include Technology-enhanced Language Learning and CALL, Online Testing and Language Assessment and Neuro/cognitive Linguistics.

Dr Khalid Saeed Al-Shahrani is currently an Assistant Professor and Branch Director at the English Language Institute, Royal Commission of Jubail, Saudi Arabia. $\mathrm{He}$ has $\mathrm{PhD}$ in the use of eLearning technologies in teaching and learning from Monash University, Australia. He is a member of the National Scientific Committee for writing the new standards of English Language Curriculum in the public school system in Saudi Arabia. He published a number of book chapters and articles and he is the main the editor of a Routledge book published in 2017 titled "Transforming Education in the Gulf Region: Emerging learning technologies and innovative pedagogy for the 21st century".

Article submitted 24 August 2018. Resubmitted 15 October 2018. Final acceptance 11 November 2018. Final version published as submitted by the authors. 